Trivium: Estudos Interdisciplinares, Ano XIII, Ed. 2. p. 21-36

http://dx.doi.org/10.18379/2176-4891.2021v2p.21

\title{
O insuportável do enigma feminino em um caso de autolesão na adolescência
}

\section{Rebeca Espinosa Cruz Amaral*} Luciana Gageiro Coutinho**

\begin{abstract}
Resumo
Este artigo construiu-se a partir do estudo do caso de uma adolescente que se autolesionava, prática cada vez mais notável entre adolescentes, sobretudo meninas. Analisando a singularidade do agir no caso, extrai questões concernentes a sua relação com a mãe e ao enigma do feminino, trazidas inicialmente através de queixas à mãe, que puderam ao longo do atendimento se desvelar em uma demanda de amor formulada em nome próprio. Visa, portanto, trazer aportes teóricos sobre o tornar-se mulher na adolescência e suas possíveis relações com as autolesões praticadas por meninas através da análise do caso articulada a uma revisão bibliográfica.
\end{abstract}

Palavras-chave: AUTOLESÃO; ADOLESCÊNCIA; FEMININO.

\section{The unbearable female enigma in a case of self-injury in adolescence}

\begin{abstract}
This article was built from the study of the case of a self-injury teenager, an increasingly notable practice among teenagers, especially girls. Analyzing the singularity of acting in the case, it extracts questions concerning her relationship with the mother and the enigma of the feminine, initially brought about by complaints to the mother, which were able during the treatment to unveil itself in a demand for love formulated in her own name. Therefore, it aims to bring theoretical contributions about becoming a woman in adolescence and its possible relationship with self- injury practiced by girls through the analysis of the case articulated to a bibliographic review.
\end{abstract}

Keywords: SELF-INJURY; ADOLESCENCE; FEMALE.

\section{L'insupportable de l'énigme féminine dans un cas d'automutilation à l'adolescence}

\section{Résumé}

Cet article est construit à partir de l'étude du cas d'un adolescent qui s'auto-lésione, une pratique de plus en plus notable chez les adolescents, en particulier chez les filles. Analysant la singularité de l'agir dans le cas clinique, il extrait des interrogations concernant a sa relation avec la mère et a l'énigme du féminin, initialement apportées par des plaintes à la mere, qui ont pu se dévoiler pendant le traitement dans une demande d'amour formulée en son propre nom. Il vise donc à apporter des apports théoriques sur le devenir femme à

\footnotetext{
* Doutoranda em Teoria Psicanalítica pela Universidade Federal do Rio de Janeiro com bolsa da Capes. Mestre em Teoria Psicanalítica pela Universidade Federal do Rio de Janeiro. Psicóloga pela Universidade Federal Fluminense.

ORCID ID: https://orcid.org/0000-0001-5011-5226

E-mail: respinosacamaral@ hotmail.com

** Doutora em Psicologia Clínica pela Pontifícia Universidade Católica do Rio de Janeiro. Professora Associada da Faculdade de Educação da Universidade Federal Fluminense.

ORCID ID: https://orcid.org/0000-0001-5535-5931

E-mail: lugageiro@uol.com.br
} 
l'adolescence et ses possibles relations avec l'auto-lésion pratiquée par les filles à travers l'analyse du cas articulé à une revue bibliographique.

Mots-clés: AUTO-LÉSION; ADOLESCENCE; FÉMININ.

\section{Introdução}

Em 1927, no pós-escrito ao texto sobre a análise leiga, Freud afirma que a psicanálise possui a peculiaridade de ser o único método no qual investigação e cura coincidem, não só porque o conhecimento traz algum êxito terapêutico, mas principalmente por ser impossível tratar um paciente sem apreender algo de novo.

Partindo disso, podemos compreender a psicanálise como uma teoria, um método terapêutico e um método de pesquisa, assim como podemos compreender Freud como um pesquisador, um teórico e um clínico, testemunhando em sua obra a favor da indissociabilidade destes termos. A psicanálise, enquanto tratamento, já é por si só um método de investigação, de modo que a obra de Freud nos ensina que, para a elaboração de uma pesquisa em psicanálise, o fundamental é a construção do objeto a ser estudado, a partir do método utilizado para recortá-lo, ou seja, é o método interpretativo de Freud que produz seu objeto de pesquisa, o inconsciente.

Os objetos da psicanálise são as formações do inconsciente, mas estes não estavam assim postos de antemão, pelo contrário, eram objetos relegados pela ciência por produzirem um furo no saber. Dessa forma, Freud subverte o saber, produzindo sua questão a partir de sua implicação, apontando-a como eticamente implicada com a produção do sujeito que só se dá na transferência. Assim, Freud se desfaz das certezas apriorísticas e mergulha nas cenas se deixando apanhar pelo enigma, e produz um saber que condiz com seu lugar na psicanálise em sua transmissão e herança, construindo aí seu lugar de enunciação.

É, portanto, desde a obra de Freud, que temos como instrumento e ferramenta da pesquisa em psicanálise o estudo de caso clínico, que consiste em um "relato de uma experiência singular, escrito por um terapeuta para atestar seu encontro com um paciente e respaldar um avanço teórico" (Nasio, 2001, p.11), pois a pesquisa permanente, dirigida pela escuta, é o que permite que nos defrontemos com o singular e possamos problematizar a teoria na tentativa de apoiar seu avanço. Entendemos que a escrita de um caso, como ato de linguagem, testemunha a clínica e fornece não exatamente respostas, mas suscita questões e reflexões sobre o modo singular como o sujeito pode se confrontar com sua experiência subjetiva, e que escrever um caso comporta também o impossível de escrever, que numa escrita acadêmica deve ser sustentado eticamente, não encobrindo os furos.

Assim, é seguindo a trilha aberta por Freud de uma escrita ética que se sustenta pela escuta do sujeito do inconsciente e pelo desejo do analista, e que se vale do que pode operar na transferência, que construímos o presente artigo, um estudo de um caso atendido, durante o curso de Especialização em Psicanálise e Psiquiatria com Crianças e Adolescentes do IPUB/UFRJ ${ }^{1}$. Formular um trabalho a partir de um caso clínico é uma experiência enriquecedora, por este motivo, optamos aqui não por fazer uma divisão entre teoria e o caso, mas ir trazendo-os conjuntamente, o desenrolar do caso atravessado pelas reflexões a respeito do mesmo. Deste modo, esta introdução se iniciará também com a introdução do caso, para que, a partir disto, possamos avançar nas construções teóricas a ele associadas.

A paciente, que chamaremos aqui de Maria Eduarda ${ }^{2}$, foi encaminhada ao serviço pelo psiquiatra da clínica da família de sua região com queixa relativa à prática de cortes pelo corpo. Na triagem do serviço, quando tinha treze anos, compareceu acompanhada pela mãe, Sandra, e relatou ter sido encaminhada para atendimento psicológico após o psicólogo de sua escola notar cortes em seu braço. Disse que se cortava com gilete, faca ou tesoura quando ficava estressada ou triste, às vezes com coisa grandes, como mágoas com o pai, ou em 
outras, com coisas rotineiras e bobas, como ter que realizar tarefas em casa. Quando questionada se algo aconteceu na época em que começou a se cortar, mencionou que sua mãe dava mais atenção aos seus irmãos e que, quando um de seus irmãos saiu de casa, ela se sentiu abandonada. $\grave{A}$ pergunta se conseguia se comunicar quando chateada ou decepcionada respondeu que não, que apenas guardava para si e se cortava, e que estava feliz e aliviada que teria alguém com quem conversar agora. A partir do início dos atendimentos, as reflexões que se seguem começaram a delinear-se em torno da questão da (re)descoberta do feminino na adolescência ${ }^{3}$.

Tendo tudo isso em vista, dividiremos nosso trabalho em quatro tópicos centrais. No primeiro destes, abordaremos as queixas de Maria Eduarda e buscaremos demonstrar como essas dizem respeito ao momento da adolescência que reatualiza questões para o sujeito e o relança no campo do desamparo ao confrontá-lo com sua condição de falta-a-ser. Em seguida, traremos as mensagens endereçadas à mãe que começaram a delinear-se em meio às queixas, e pensaremos como, ao poder falar sobre isto, ela pôde começar a buscar outros caminhos para a construção de respostas para suas questões. A partir deste, abordaremos as construções de suas demandas ligadas ao enigma do feminino e articuladas em nome próprio, o que nos encaminhará a um derradeiro tópico, em que buscaremos trabalhar as articulações entre o feminino, o desamparo e a angústia, tal como o caso nos permitiu elucidar.

\section{Queixas}

A prática da autolesão, também conhecida como cutting ou escarificações, tem estado cada vez mais presente na atualidade, tanto em consultórios como em serviços de saúde em geral, e vem-nos alertando para a presente forma de manifestação do mal-estar no registro corporal. Já codificada pelos manuais psiquiátricos, insere-se no DSM como um dos tipos das chamadas autolesões não suicidas e independentes de outros transtornos. Estas dizem respeito a comportamentos intencionais de agressão direta ao corpo como queimaduras, mordidas, arranhões e cortes autoinfligidos, realizados de maneira repetitiva, e com frequência visando a obtenção de alívio de sentimentos negativos, resolução de questões pessoais, e/ou direcionamento a estados positivos de sentimentos.

Diversos autores da psicanálise e da antropologia (Le Breton, 2010; Fortes \& Macedo, 2017; Araújo, Scheikman, Carvalho \& Viana, 2016; Costa, 2003) vêm demonstrando que o aumento da prática da autolesão entre adolescentes está relacionado ao fato de que tais atos têm sido vistos, muitas vezes, como único recurso frente à angústia e ao desamparo que os atingem durante o "adolescer". A adolescência, desde seu surgimento na Modernidade (Coutinho, 2009), sempre foi acompanhada de algum sofrimento, mas, na atualidade ${ }^{4}$, tem sido cada vez mais comum o relato de jovens sobre o peso que essa travessia implica em termos de sentimentos angústia e de solidão, desamparo e uma dor de existir cujo excesso só se alivia, mesmo que apenas momentaneamente, pela dor física do corte.

Mas, além do crescimento geral desta prática na contemporaneidade, o que chama atenção é o fato de que ela se dá principalmente entre adolescentes do sexo feminino, que a procuram, divulgam e falam sobre em diversas plataformas da internet (Fortes \& Macedo, 2017). Nestas, elas dividem entre aquelas que também a praticam seus modos de descarga do excesso que as aflige, suas fragilidades, carências, experiências de esvaziamento, falta de sentido e ausência de um interlocutor com que conversar sobre isso tudo. Assim, pode-se supor que o pano de fundo para tais práticas é uma experiência de desamparo com prejuízo na possibilidade de construir uma narrativa e um endereçamento para a sua dor, de forma que a descarga possível não se dá por meio de palavras, o que mostra que há algo aí que não consegue ser simbolizado e nomeado e que, por isso, se manifesta em ato no corpo. 
Cavalcanti \& Poli (2015) afirmam que o desamparo presentifica uma situação onde o sujeito é invadido pela pressão constante e excessiva de forças pulsionais, tendo que erguer circuitos que o ajudem no domínio dessas intensidades e criar representações simbólicas que tornem possível desviá-los renovadamente. As autoras ressalvam ainda que tal desamparo deve ser analisado na singularidade de cada caso, pois ele

se singulariza na história de cada sujeito, a partir da relação de dependência com aquele ou aquela que cuida, que se tornará responsável em lhe transmitir a vida psíquica caracterizada pela impossibilidade do neném em lidar com as exigências pulsionais, sobretudo pela inexistência de um aparelho psíquico ao nascer (Cavalcanti \& Poli, 2015, p. 66).

Tal ressalva é fundamental pois nos alerta para a importância de nossa escuta e análise no um a um. No caso de Maria Eduarda, por exemplo, no seio de sua condição de adolescente já destacada, vemos que suas queixas se centram em torno questões familiares, principalmente sua relação com o desejo do Outro materno. A partir destas e com o decorrer do trabalho analítico, elas puderam se desdobrar, como veremos, em demandas pela via da palavra a respeito de sua condição feminina, deixando claro que o que estava em jogo para ela em seu processo de adolescer era o confronto com o enigma do feminino, diante do qual tentava incessantemente convocar sua mãe a lhe dar uma resposta.

Na primeira sessão agendada com Maria Eduarda, ainda na recepção do ambulatório, notou-se a distância entre ela e a mãe, pois apesar de todas as cadeiras estarem desocupadas, elas haviam sentado deixando uma cadeira vazia entre elas. Já na sala, ao ficar sozinha com a psicóloga a menina afirmou que se autolesionava principalmente por sua mãe não lhe dar atenção, ter preferência por seu irmão mais velho e viver em função do namorado. Reclamou de não ter ninguém para conversar, contando que, quando dizia à mãe que precisava conversar com ela, essa não lhe dava atenção. Queixou-se também de ver pouco a mãe por esta trabalhar de terça a domingo, o dia todo, e relatou que a primeira vez em que se cortou foi quando foi deitar-se perto da mãe e esta se afastou dela, aproximando-se do namorado que estava deitado do outro lado. Disse ser muito sensível, guardar muitas coisas para si e depois acabar se cortando.

Desde essa primeira sessão, ficou claro que o bojo sintomático de Maria Eduarda estava associado às suas relações familiares e ao desejo do Outro materno, o que se fez notar em todas as sessões posteriores, nas quais tais queixas se repetiam incessantemente, por vezes acrescidas de alguns detalhes. A menina reclamava que sua mãe não olhava para ela, não tinha nem visto seus cortes, não a ajudava mais a escolher suas roupas e nem opinava sobre sua aparência, não a ouvia, não lhe dava atenção quando ela queria contar sobre os meninos com que estava ficando, não havia conversado com ela quando ela ficou menstruada pela primeira vez e nem quando, em suas palavras, se "perdeu" - referindo-se à sua primeira relação sexual; não saía com ela, apenas com o padrasto, e só gostava de seu irmão mais velho. ${ }^{5}$ Suas queixas revelam, então, uma menina às voltas com os melindres relativos à adolescência, na qual, como veremos, confrontada com o real do sexo, são retomadas pelo sujeito as questões referentes ao desamparo, à castração, às suas relações com as figuras parentais e à tomada de uma posição sexual a partir disso. Faz-se assim necessário, neste momento, um delineamento das especificidades da constituição subjetiva do sujeito adolescente.

A adolescência não é em si um conceito psicanalítico; na verdade, na obra de Freud, praticamente não encontramos essa palavra, fazendo referência apenas ao termo "puberdade" em seu texto de 1905/1996b, cuja terceira parte se destina a discutir o que nomeia como As transformações da puberdade. Entre esses dois conceitos, adolescência e puberdade, muitas 
diferenças são apontadas, mas, essencialmente, dizem respeito ao fato de a puberdade referirse às mudanças biológicas e físicas que se dão, enquanto a adolescência diz respeito às transformações psíquicas, sociais, culturais, etc., que se dão a partir da puberdade. É por isso que, para entendermos a adolescência temos que considerar além da dimensão biológica, também o contexto social e cultural em que o sujeito está inserido (Birman, 2006).

Deste modo, quando afirmamos que Freud não fala da adolescência como conceito, não estamos dizendo que ele não se refira a ela. No próprio texto de 1905 que citamos, por exemplo, Freud afirma que nesse período que ele está chamando aqui de puberdade, introduzem-se mudanças que levam à vida sexual normal em sua forma final. Neste momento, a pulsão (re)encontra o objeto sexual, surge um novo alvo sexual para cuja consecução se conjugam as pulsões parciais, e as zonas erógenas subordinam-se ao primado da zona genital. Todas essas transformações, como bem sabemos, não tratam apenas de mudanças biológicas, já que não se trata aqui apenas do indivíduo físico, mas de um sujeito pulsional e seus processos.

Com isso, acreditamos que as contribuições de Freud em 1905/1996b não tratem apenas da puberdade, mas do que chamamos de adolescência, pois ele discute a respeito das repercussões psíquicas geradas por tal etapa de ruptura com a vida infantil e travessia rumo à vida adulta. Na passagem do corpo pulsional infantil para o corpo pulsional adulto, está em jogo a inclusão de uma posição sexuada e a construção psíquica da imagem do corpo púbere, que vai ganhando forma com as modificações corporais biológicas. Com isso, o sujeito é convocando a simbolizar o real que irrompe, lançando mão de estratégias para dar conta da angústia decorrente justamente desse excesso pulsional. Isso é reafirmado com as contribuições lacanianas trazidas por Alberti (2004) de que a adolescência diz respeito centralmente ao encontro necessariamente faltoso do sujeito com o real do sexo, pois é exatamente disso que em outras palavras também trata Freud.

Além disso, ao falar a respeito da aquisição de um novo corpo, genitalizado, Freud (1905/1996b) refere-se também ao remanejamento dos referenciais identificatórios, e deixa claro como há, no campo psíquico, uma reatualização do Complexo de Édipo - que até então estava em suspenso pela entrada do sujeito no período de latência - que confronta o sujeito com as questões relativas à sexuação. Na adolescência, trata-se de poder abandonar os pais como objetos de desejo, para que se possa investir em novos objetos, trabalho que, por vezes, é árduo para o sujeito, mesmo este já estando sob o julgo da interdição do incesto visto que também implica um remanejamento identificatório e a assunção do ser para o sexo. Vale destacar, porém, que o abandono dos pais como objetos de desejo não significa que essas relações percam sua função, pois, como Freud (1905/1996b) deixa claro, elas serão sempre um referencial importante para os posteriores investimentos.

Nessa operação de desligamento dos pais da infância, o adolescente precisa, entretanto, da presença dos pais, por mais paradoxal que pareça, como marca Alberti (2004). Os pais precisam estar lá para que o adolescente possa elaborar suas escolhas, perdas, fazendo uso das direções e os indicativos que recebeu desde a infância. Esta operação diz respeito à elaboração da falta no Outro, que tensiona a alienação inaugural e aponta para separação - não do Outro incorporado, mas dos pais imaginarizados -, que só terá êxito se a incorporação dos pais tiver ocorrido, garantindo certa proteção contra o desamparo fundamental. Pois,

O adolescente deve saber que não há como escapar do desamparo fundamental intrínseco ao ser humano, por mais dolorosa que seja essa constatação ele já sabe que o Outro não pode protegê-lo, apenas enriquecê-lo com algum recurso para encarar o desamparo sozinho. Há vários nomes para isso em psicanálise, o mais divulgado é o conceito de castração. [...] Para aceder ao desejo é necessário o reconhecimento da castração da qual, aliás, o desejo se alimenta! Os pais também são castrados e é por 
isso que o filho pode deixá-los, levando consigo a melhor bagagem que puder recolher! Poder encarar o desamparo, as impossibilidades, submeter-se à castração simbólica é o longo trabalho de elaboração da falta no Outro que diz respeito à adolescência (Alberti, 2004, p. 16).

Todo esse processo, porém, envolve também os pais, que nem sempre têm facilidade de lidar com tudo isso. Alberti (2004) afirma que, por vezes, é difícil para esses sustentar a adolescência de seus filhos, principalmente porque nesse período, na tentativa de se separarem, eles os criticam e atingem para tentar enfraquecê-los, de modo que os pais precisam suportar o aniquilamento operado pelos filhos. Ela destaca que, com isso, há vezes em que os pais desistem de desempenhar suas funções e acabam sendo eles que se separam dos filhos. Com isso, transmitem aos filhos um sentimento de abandono, diante do qual os adolescentes podem ter uma série de comportamentos e atitudes que consistem numa tentativa desesperada de chamar a atenção dos pais.

No que concerne a este último fato, é importante, como sempre, termos em mente a singularidade do caso a caso. A partir de sua experiência clínica, por exemplo, Flesler (2012) afirma que se em alguns casos os pais chegam sentindo-se perdidos e angustiados pelo sintoma da criança e procurando um saber que possa decifrar o mistério encerrado no sintoma do filho e solucioná-lo, em outros nos chegam pais que não questionam e buscam a análise apenas com uma demanda de ajustamento da criança que ao se revelar diferente do esperado por eles lhes feriu o narcisismo. Há outros, ainda, que nada demandam, chegam apenas por uma exigência de outra instituição.

Tudo isso nos faz notar que não podemos perder de vista a postulação de Lacan, em 1969/2003, de que o sintoma da criança diz muito da estrutura familiar, aparecendo como representante da verdade do par familiar ou dizendo respeito à subjetividade da mãe. Deste modo, podemos dizer que o sintoma da criança/adolescente em análise diz algo da estrutura de sua família, de suas relações, vindo em lugar da palavra que falta e sendo, por meio dele, que a família pode repensar suas histórias e relações.

$\mathrm{Na}$ contemporaneidade, isso aparece ainda de forma mais latente visto que, como demonstra Saggese (2015), no mundo pós-tradicional a adolescência é marcada pela indefinição, pois a construção de sua identidade e o significado das normas sociais não são mais ofertados pela tradição através dos ritos de passagem, mas são responsabilidade do jovem em um meio onde oportunidade e perigo estão equilibrados. Neste, os adolescentes questionam como obter uma estabilização de seu lugar no laço social, já que lhes falta um sentido predeterminado para suas mudanças, o que os faz muitas vezes buscar identificações imaginárias, baseadas principalmente no corpo, quando o referencial do Outro se fragmenta. Todas essas observações nos encaminham à necessidade de pensarmos um pouco mais a respeito do estatuto do Outro para o sujeito, desde a sua constituição, e de como a relação com o primeiro Outro, essencialmente materno, está em jogo no adolescer feminino e no caso de Maria Eduarda. É o que faremos a seguir.

\section{Mensagens}

Em seu livro intitulado Os outros em Lacan (Quinet, 2012), Antônio Quinet afirma que para a psicanálise, seguindo os ensinamentos de Freud e Lacan, não há sujeito sem Outro. Para a psicanálise, o sujeito não é o eu ou o indivíduo, ele é relacional - e tridimensional na medida em que Lacan pensa a realidade a partir de três registros que se amarram de maneira particular a cada um no nó borromeano: real, simbólico e imaginário - e constituído a partir do Outro, que o insere no campo da linguagem. Em outras palavras, somos sujeitos quando emergimos no campo da linguagem. 
Assim que nasce, a criança é um ser prematuro, não tem qualquer condição de sobreviver sozinha, é um conjunto de ossos e órgãos, no qual o sujeito ainda está por se construir e precisa de alguém que o ampare e dê suporte a essa constituição, tanto de sentidos quanto de cuidados. Esse papel deve ser desempenhado pelo Outro, que opera como uma função responsável por introduzir, através da linguagem e do desejo, o corpo de órgãos no campo da subjetividade. A partir da emergência de um Outro que nomeia e banha o corpo do infante com os seus significantes, temos a constituição de um sujeito: sujeito que fala, sujeito da falta.

Inicialmente, quem ocupa o lugar do Outro são os cuidadores da criança, de modo que as primeiras relações libidinais com aquele que assume a posição de cuidá-la são o que dá base à sua constituição enquanto sujeito, ou, em outras palavras, o que conjuga o Outro ao sujeito é uma dialética do desejo. Como já foi dito, em Freud (1905/1996b), a constituição do psiquismo através de seu desenvolvimento psicossexual culmina no complexo de Édipo, que, na leitura lacaniana (Lacan, 1956-1957/1995) deixa de ser entendido como romance familiar, e passa a ser lido a partir de um esquema triangular vetorizado pelo significante fálico, sendo, portanto, a partir desse complexo que o sujeito pode se organizar através de uma construção sintomática em torno da falta.

A travessia entre o espaço intra e extrafamiliar, porém, que se dá na adolescência, quando o sujeito tem que tomar a palavra e deixar o escudo do Outro familiar, respondendo às questões existenciais da vida num período onde percebe a inconsistência do Outro - pois o pai do ideal não encontra correspondente no da realidade, é comumente uma experiência de desvanecimento do sujeito, como observa Sagesse (1996). É esse desvanecimento que estará na raiz das várias crises na adolescência, nas quais os sintomas são respostas possíveis a isto que aponta para o insuportável e está ligado ao ponto de falta do desejo materno que justificaria nossa existência, e a dor do desligamento da autoridade dos pais - entendida como toda consistência esperada do Outro paterno que se dissolve aos olhos do adolescente. Tal destituição subjetiva, segundo o autor, é o objetivo de toda análise, mas, no caso do adolescente, por ser brutalmente exposto a ela, produz respostas sintomáticas para tentar se esconder. Por isso, o autor destaca que ao contrário do que a prática médica prega hoje, existe uma dor incontornável no adolescer, que não pode ser encerrada por fármacos, já que é fruto da tensão entre o sujeito adolescente e o Outro, de modo que, enquanto fenômeno sociocultural, a adolescência não pode ser tratada como uma patologia, o que não significa negar a existência de situações de grave sofrimento psíquico na adolescência.

Por isso, durante a adolescência pode haver momentos em seja necessário o sujeito retornar à ilusória relação que tinha com os pais, na tentativa de suportar a separação, mas aos poucos o sujeito vai conseguindo se descolar deste bastião (Alberti, 2004). Acreditamos que, de certa forma, seja esse caminho de ir e vir em relação aos pais da infância que Maria Eduarda começa a sutilmente percorrer em seu trabalho analítico ao poder falar mais sobre o que estava em questão em suas práticas de autolesões e em sua relação com sua mãe.

Tal associação entre os cortes e a mãe já se fazia notar, desde o início dos atendimentos, quando ela envia a psicóloga uma mensagem dizendo que no dia anterior havia se cortado, pois, em suas palavras: "Tudo que acontece dentro de casa ou se ela se estressa na rua, a minha mãe desconta em mim. Eu já tava guardando isso há muito tempo e ontem eu não aguentei e acabei me cortando, porque eu tava com muita raiva". Em uma sessão, alguns meses depois, o ato de se cortar começa a clarificar uma mensagem mais explicitamente endereçada ao Outro quando ao chegar, ela coloca os braços desnudos sobre a mesa e pode-se ler nos cortes a escrita da seguinte frase "Eu sou um lixo". Questionada se gostaria de falar sobre aquilo, contou que havia escrito no dia anterior por estar magoada com um menino com o qual estava se relacionando, mas também magoada e com raiva de sua mãe. Deslizando sua fala do menino à mãe, disse que estava assim por ela descontar nela própria todos os seus 
estresses, achar que tudo que ela fazia era errado, e dizer que era drama, mandando-a arrumar a casa. Acrescenta ainda que a mãe coloca nela a culpa de tudo de errado que acontecia em casa e não a ouve, como faz com seus irmãos - a quem chama para conversar quando fazem coisas erradas; mas apenas acusá-la.

Esta escrita no corpo foi uma das primeiras vezes em que Maria Eduarda conseguiu colocar seus sentimentos em palavras, cifrá-los, embora aqui ainda muito alienada à mãe, ao que dizem dela, no lugar de objeto dejeto, lixo. Ao se queixar e falar da raiva, do sentimento, entretanto, pôde começar a deslizar um pouco desse lugar alienado que os cortes e o agir fazem notar, e formular uma demanda, que minimamente traz algo de uma tentativa de separação, diferenciação.

\section{Demandas}

Desde o início de seus atendimentos, as queixas de Maria Eduarda direcionavam-se muito ao fato de a mãe não conversar com ela e não olhar pra ela, não ajudar com suas roupas, não opinar sobre seus namorados, e não lhe contar as coisas sobre sua vida, suas questões com o padrasto, suas idas ao médico, etc. Após um longo percurso de queixas em que apesar das intervenções da psicóloga a menina não deslizava de tais reclamações, numa sessão em maio de 2020, ela conseguiu dizer que queria aprender coisas com a mãe, queria conversar com esta por ela ser mulher. Questionada sobre o que achava que a mãe poderia lhe ensinar, disse que coisas de menina, dizendo que a mãe era muito vivida, já tinha passado por muitas coisas e ela achava que a mãe poderia ensiná-la. Ela disse que a mãe sabia muitas coisas e nunca conversou sobre nada com ela. Tal elaboração de Maria Eduarda deixa clara sua demanda da mãe por uma resposta a respeito do feminino.

O que quer uma mulher? O que é uma mulher? Parece serem essas essencialmente as questões para as quais Maria Eduarda demanda uma resposta. Questões enigmáticas não só para ela, mas para o sujeito e para a própria psicanálise, já que Freud em 1933[1932]/1996h já dizia ser a pergunta a respeito do desejo feminino impossível de responder. E, que com Lacan, compreendemos ser um enigma que advém inicialmente da impossibilidade de representação do sexo materno. Para que possamos melhor compreender o que está em jogo no caso, é importante, portanto, que retomemos as teorias referentes à constituição do sujeito no que esta tem de particular no feminino. Queremos deixar claro, porém, que não nos alongaremos aqui em todos os melindres referentes às teorizações psicanalíticas a respeito do feminino, mas daremos um enfoque ao que tange à relação da menina com sua mãe neste processo, visto ser isto que está centralmente em jogo no caso que aqui norteia esse estudo.

Para começar, é importante trazer a ressalva feita por Poli (2007), de que apesar de inicialmente Freud ter proposto a anatomia genital como principal apoio na definição dos destinos da sexualidade infantil a partir da presença ou ausência do pênis no complexo de castração - onde os meninos temem serem privados do mesmo e as meninas se deparam com a perda já realizada e desenvolvem o que ele chama de inveja do pênis - a correspondência anatômica não é suficiente para a assunção no sujeito de uma posição sexuada. Como ela demonstra, Freud, desde 1905/1996b, aponta a autonomia e independência das funções sexuais em relação à biologia. E sua escuta é testemunha do sofrimento do qual padece o neurótico "da tentativa de construir uma imagem que possa corresponder ao que supomos ser um homem ou ser uma mulher [onde a grande questão é] "o que o Outro quer de mim?" (Poli, 2007, p. 11).

Retomando brevemente o percurso a respeito da diferença sexual na obra de Freud com um enfoque maior para o campo do feminino. Temos nas obras freudianas de 1905/1996b e 1908/1996c um primeiro momento em que ele se debruça sobre a sexualidade infantil e fala a respeito do Complexo de Castração e da Inveja do Pênis. Será, porém, em 
1924/1996 que, ao retomar esta questão, irá dissertar mais sobre o desenvolvimento sexual feminino, afirmando que as meninas também desenvolvem um complexo de Édipo, um supereu e um período de latência, aos quais também podemos atribuir uma organização fálica e um complexo de castração, mas todos esses processos acontecem de uma maneira particular.

Isso porque as meninas explicam a falta do pênis presumindo que já o tiveram, mas o perderam por castração, sentindo-se com isso injustiçadas e inferiores. É por isso que Freud (1924/1996) credita às meninas uma aceitação da castração como um fato consumado, ao contrário dos meninos, que temem a possibilidade de sua ocorrência. Essa distinção será ainda retomada por ele no texto Algumas consequências psíquicas da distinção anatômica entre os sexos (1925/1996f), onde retoma a ideia de inveja feminina do pênis e afirma que na medida em que na menina a castração já foi executada, é ela que introduz o complexo de Édipo. A partir de seu sentimento narcísico de humilhação ligado à inveja do pênis, ela é forçada a afastar-se da masculinidade e toma novas linhas que conduzem para ao desenvolvimento da feminilidade. Com isso,

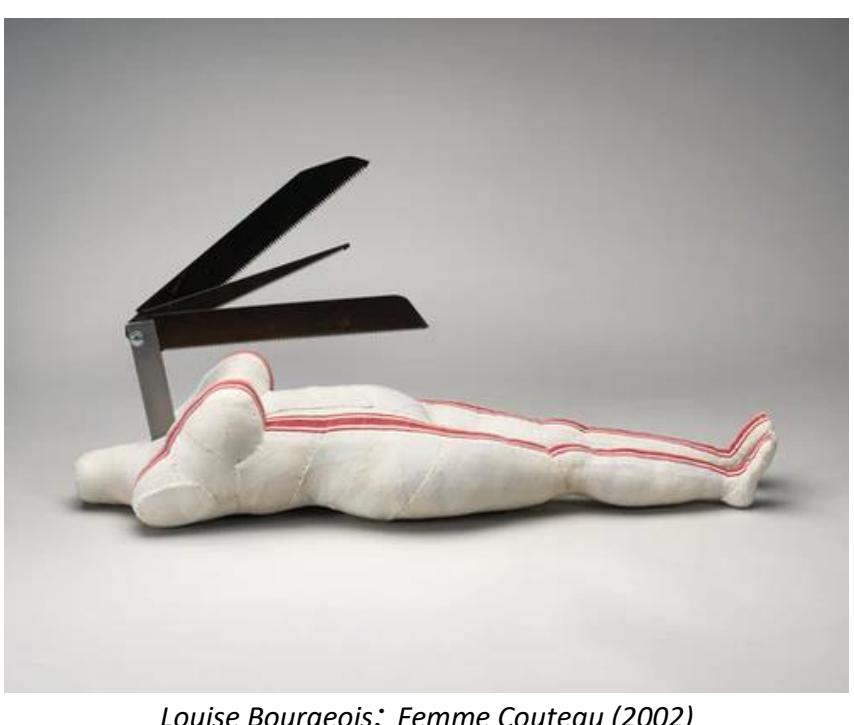

Louise Bourgeois: Femme Couteau (2002)

ela abandona seu desejo de um pênis e coloca em seu lugar o desejo de um filho; com esse fim em vista, toma o pai como objeto de amor. A mãe se torna o objeto de seu ciúme. A menina transformou-se em uma pequena mulher (Freud, 1925/1996f, p. 288289).

Assim, sobre a diferenciação entre a operação da castração nos meninos e nas meninas, e a partir do pressuposto de que a mobilização edipiana gira em torno da castração, podemos afirmar, seguindo Freud, que diante da ameaça de castração: o menino se submete à autoridade paterna buscando na relação ao pai uma identificação, enquanto a menina percebe que a mãe não lhe dará o suporte para que ela possa se valer do falo e, com isso, abdica do amor à mãe e se submete ao amor paterno - substituindo o desejo pelo falo pelo desejo de um bebê e tomando o ideal como âncora do que buscará nas relações amorosas -, passando a buscar na mãe uma identificação para sua tomada de posição no campo do feminino.

Mas aqui, é importante trazer ainda outro importante apontamento feito por ele, o de que em meninas e meninos, apesar de ressonâncias diferentes, o complexo de castração se inaugura com percepção de uma falta no corpo materno, da mulher. Diante disso, enquanto o menino renuncia à mãe por tomar o pai como agente da castração desta e o temer, introjetando a Lei do incesto, recalcando suas identificações com a posição materna, e passando a tomar o pai como ideal; a menina percebe em si a mesma falta que vê na mãe, ressentindo-se com essa e voltando seu amor para o pai - portador do órgão fálico, esperando um dia que ele lhe dê o que a mãe foi incapaz, um (substituto do) falo -, enquanto passa a tentar se identificar à mãe em sua feminilidade.

Não à toa, após esses textos, Freud se volta mais diretamente a questão do feminino, tema que abordará em 1931/1996g no texto Sexualidade feminina e em 1933[1932]/1996h em A feminilidade, onde trata mais diretamente da relação da menina com a mãe no que chama de período pré-edípico. Nesses textos ele afirma que a prevalência da passividade no campo 
pulsional feminino diz respeito a impasses na transposição do complexo edípico em função da relação das meninas com a mãe, afirmando uma dificuldade de superá-la e substituí-la e uma tendência à fixação libidinal nos tempos pré-genitais onde há uma objetalização da criança frente ao desejo materno e uma atividade reversa da busca por domínio.

Apesar de nestes textos apontar a importância de certo desligamento na relação entre a menina e a mãe para que a menina possa se tornar não só mulher, mas também sujeito desejante, como compreendermos alguns anos depois com Lacan - em 1925/1996f, ele já havia afirmado que a menina nunca abandona totalmente sua posição infantil e no que esta se relaciona às suas pretensões incestuosa para com a mãe, pois a força de seu amor pela figura materna nunca é completamente transferida para seu pai. Volta a afirmar isso em 1933[1932]/1996h, quando diz que os impasses edípicos na menina se relacionam ao fato de haver em sua relação com a mãe, seu primeiro objeto de amor, uma zona obscura.

Aqui é importante pontuar que Maria Eduarda sempre dizia que seus cortes também eram culpa de seu pai, porque ele nunca lhe deu nada, ela tinha que correr atrás dele para pedir as coisas e mesmo assim ele nunca o fez. Maria Eduarda também contou que seu pai estava com uma nova companheira, tinha duas filhas com a mesma, e passou a ter menos paciência com ela e ser mais ausente. Afirma ter sempre sido sua mãe a responsável por lhe dar tudo, pois o pai nunca foi presente, é seco com ela e ela também gostaria de conversar mais com ele. Demonstra, assim, seu ressentimento com o pai que nos parece estar para além do fato dele nunca ter correspondido ao lugar de lhe dar algo, o falo-bebê, mas também em função de só muito precariamente ele ter possibilitado entre elas um corte, deixando sua mãe responsável por lhe dar tudo, de modo que nos questionamos de que tudo se trataria aqui e em que zona obscura tal fato lança Maria Eduarda.

Podemos avançar nessas questões através da retomada efetuada por Lacan que, através de sua leitura da obra freudiana, também muito dissertará a respeito da diferença sexual e da relação mãe-filha. Para começar o percurso desta temática em sua obra, é importante notar que desde o inicio da mesma - e o que traz centralmente em 1958/1998 - o autor deixa claro que a diferença sexual não tem por referencial a anatomia, mas é uma operação simbólica que se dá a partir da incidência do significante que promove efeitos de significação, ou seja, "o referente das identidades sexuais é interno à linguagem e está em causa a cada enunciação" (Poli, 2007, p. 69).

No que concerne a isso, Lacan (1957-1958/1999) destaca uma diferença do efeito do complexo de castração no menino e na menina, na medida em que para o menino a virilidade é assumida pela identificação com o pai, enquanto que para a menina o que se dá, na medida em que o pai se torna o Ideal do eu, como modelo de amor, é o reconhecimento de que ela não tem o falo. Tal processo, parte da descoberta de Freud (1908/1996c) de que os homens e as mulheres não se fazem representar no inconsciente por "símbolos" diferentes, de modo que os meninos chegam a presumir que todas as pessoas que conhecem possuem uma genitália semelhante à sua. Deste modo, ele conclui que a diferença sexual só se inscreve no inconsciente como consequência da percepção da diferença anatômica entre os sexos e que do lado feminino o que permanece é uma não-representação. Disto podemos depreender que ainda que anatomicamente existam características correspondentes ao macho e características correspondentes à fêmea, não há entre o sexo biológico e a sexualidade assumida pelo sujeito uma relação direta, o que Lacan irá explicar pelo fato de não haver um significante no Outro que venha determinar o que é ser homem ou mulher.

Ao se referir as posições de homem ou de mulher, Lacan (1972-1973/2008) refere-se aos sujeitos que as assumem como aqueles que ficam 'sob a bandeira' dos homens e aqueles que ficam 'sob a bandeira' das mulheres, o que corrobora que não há coincidência entre ser anatomicamente homem ou anatomicamente mulher e se sexuar assim, além de deixar claro também que essas são posições assumíveis em relações, podendo se alternar em diferentes 
momentos. Diante disso, fica claro que a assunção como homem ou mulher dependerá do processo que ele nomeia como sexuação (Lacan, 1972-1973/2008), e que diz respeito à inscrição sexual no plano simbólico a partir da castração, e do complexo edípico.

Levando isso em conta, Kehl (2008) afirma que "o ajuste das mulheres à feminilidade nunca é perfeito, e muito menos se dá sem conflitos" (Kehl, 2008, p.65), pois não há um significante que as ordene e ela irá rivalizar com a mãe, seu primeiro objeto de amor, em busca de um significante que a norteie em seu posicionamento frente ao Outro. Além disso, como, no caso da menina, a saída do Édipo não se dá em função de uma ameaça de perda como no menino, este não terá um desfecho tão "conclusivo", já que nada a obriga a abandoná-lo, ela não tem o que perder, sua postura é de reivindicação. A menina culpa a mãe por tê-la enviado "ao mundo assim tão insuficientemente aparelhada" (Freud, 1924/1996, p. 283), "ressente-se de a mãe tê-la trazido ao mundo como mulher" (Freud, 1931/1996g, p. 242), e reivindica desta algo com que possa se identificar como mulher. É tendo isso em vista que, em 1931/1996g, Freud afirma que a relação entre mãe e filha é uma relação de catástrofe, o que Lacan, alguns anos depois em sua releitura da obra freudiana, denominará de devastação tendo em vista a dimensão muitas vezes trágica do conflito entre elas, onde a filha é incessante nas reivindicações e isso faz a mãe confrontar-se com suas próprias questões a respeito de sua feminilidade.

\section{O feminino, o desamparo e a angústia}

O feminino, ao nos confrontar com algo relativo à falta, traz a angústia. Acima, já vimos que Freud trata dessa angústia como uma angústia de castração. Já ficou evidente que não podemos confundir o feminino com as mulheres; mas, diante de tudo isso, e tendo compreendido que diferente dos meninos, entre os quais há uma angústia de castração pela ameaça dessa, no caso das meninas, a castração é tida como já efetivada, cabe questionar, como fazem Barros \& Ligeiro (2020), de que angústia se trata nas mulheres? Freud respondeu em 1924/1996, quando afirmou que para as meninas, o correlato da angústia de castração sentida pelos meninos é o medo da perda do amor do objeto.

Em 1914/1996d, no texto a respeito do narcisismo, Freud já havia apontado que há uma diferença entre os modos como homens e mulheres amam, afirmando que no que tange às mulheres, estas amam de forma narcísica, o que buscam é mais serem amadas do que amar. Assim, o enigma do desejo do Outro confronta a mulher com o medo da perda do amor, que remete ao desamparo, fazendo frequentemente irromper a angústia.

As postulações lacanianas corroboram as freudianas na medida em que Lacan (1962-1963/2010) afirma que a angústia do homem é relacionada à detumescência - o despojamento do falo -, enquanto a das mulheres está ligada ao enigma do desejo do Outro, a grande questão: "O que o Outro quer de mim?" É essa angústia que parece atormentar Maria Eduarda frente a este enigma, e a faz demandar da mãe a todo momento respostas através de olhares e palavras, conversas, atenção. No fundo, como está no fundamento de toda demanda, ela demanda amor. Amor, que ela também suplica incessantemente aos parceiros amorosos, eleitos e logo destituídos quando é atingida novamente por uma frustração que não suporta. É tendo isso em vista que Miller (1998) localiza, também sob a denominação de devastação, o retorno da demanda de amor imposta pela mulher ao parceiro amoroso.

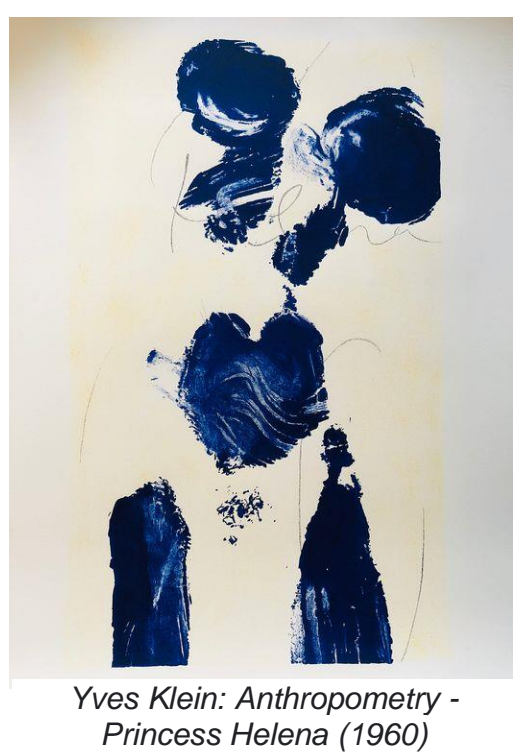


Diante do enigma do desejo do Outro e do enigma igualmente insondável de "O que é ser mulher?", a mulher se lança de forma irrestrita ao amor, a fim de que este lhe proporcione uma resposta sobre sua condição feminina, lhe dê um lugar, um suporte identificatório - reivindicado desde o Édipo - e uma saída para o desamparo. O amor possui, portanto, a função de construir sentido e suportes imaginários e simbólicos face ao real da angústia. As mulheres buscariam no amor uma possível resposta ao "O que o Outro quer de mim?", na tentativa de encontrar seu lugar de objeto no desejo do homem. [...] Este é um fato que se revela extremamente notável na clínica, onde as mulheres descrevem de forma intensa a paixão insubstituível e definitiva pelo "homem da sua vida", ou por "aquele a quem vai amar para sempre", lugar que é reeditado e atribuído a outro homem, numa nova parceria (Barros \& Ligeiro, 2020, p. 10-11).

Assim, os caminhos da análise de Maria Eduarda nos apontam para este ponto, que entrelaça todas as ideias trazidas ao longo do artigo a partir de suas falas. Nossa menina adolescente - que se está confrontando com o real do sexo - demanda através dos cortes, queixas e mensagens, pelo amor do Outro. Este, ainda essencialmente materno, deve responder-lhe a respeito dos enigmas da feminilidade e de seu desejo, mas sua não resposta a fixa na frustração e a atinge como uma grande angústia, que a remete ao desamparo e que, para ser ao menos momentaneamente aliviada, é extravasada no corpo num acting out.

Ao longo do processo analítico, porém, acompanhamos Maria Eduarda podendo passar dessa demanda através de um agir, acting out, à elaboração e construção da mesma no campo da palavra e da fala, podendo, assim, se implicar um pouco mais em seu discurso. Diante disso, recorremos a Elia (2004), que afirma não ser possível conceber a demanda sem a intervenção do desejo, pois há na primeira uma mentira estrutural que torna impossível sua satisfação plena, visto que ela promove o desprendimento dos objetos ao articular as necessidades do sujeito pela linguagem. Em sua verdadeira estrutura, portanto, ela já é desde sempre habitada pelo desejo que marca para ela a impossibilidade de satisfação.

Quando falamos, portanto, que Maria Eduarda começa a deslizar em direção à construção de uma demanda em nome próprio, é por acreditarmos que ainda que muito sutilmente ela começa a se implicar em suas queixas e a articular suas demandas ao desejo, o que faz parte do próprio trabalho da adolescência. Ao poder falar sobre aquilo que sentia, colocando em palavras sua dor e sua raiva, acreditamos que a menina pôde iniciar um processo de se confrontar com suas faltas e deslizar do campo de uma demanda alienante ao Outro através dos cortes, à construção de uma demanda minimamente disjunta do Outro e articulada ao desejo, que a implica subjetivamente e revela a enorme frustração que advém de sua relação com a mãe, bem como em relação às questões endereçadas a ela a respeito do enigma do feminino.

Dito tudo isso, podemos, então, nos dirigir às nossas considerações finais. Vale dizer que as mesmas não têm valor de conclusões e nem serão trazidas como tais, de modo que nem assim serão nomeadas, mas sim, como costuras finais, onde novamente a partir do caso traremos últimos apontamentos a partir de todo o tratado até aqui.

\section{Costuras Finais}

Na sequência das sessões acima relatadas e durante o período de isolamento social imposto pela pandemia da covid-19 que atingiu o Brasil em 2020, Maria Eduarda fugiu de casa e retornou três dias depois. Alegou durante uma sessão, após seu retorno, tê-lo feito por todas as queixas trazidas anteriormente e numa tentativa de que talvez dessa forma a mãe a notasse e sentisse sua falta. Decepcionou-se, porém, ao retornar e notar que nada havia 
mudado, a mãe nem conversou com ela sobre a fuga. Numa sessão com Sandra, esta disse que não conversava com a filha por esta não se abrir com ela, mas contou que naquele dia pela manhã a filha havia deixado uma carta para ela e que depois elas iriam conversar. Questionada sobre o porquê de só depois, já que estavam ambas em casa, ela disse que sempre que a filha queria lhe dizer algo, primeiro ela escrevia e depois ia falar com ela. Foi apontado para ela que a escrita de sua filha já era um modo de convocá-la, então talvez fosse importante que ela tomasse a iniciativa de dizer que havia visto a carta e chamá-la para conversar, mas ela não o fez. Na sessão seguinte com Maria Eduarda, a menina disse que tudo que estava acontecendo em sua casa lhe estava fazendo sentir vontade de se cortar, que ela vinha tentando aliviar escrevendo, mas que sua mãe, quando a via escrevendo, dizia que ela estava escrevendo mal dela.

Alguns dias após essa sessão, enviou à psicóloga uma mensagem de texto pelo celular da mãe - o qual utilizava para se comunicar, visto estar sem um próprio - queixando-se da falta de atenção materna. Na sessão seguinte, disse que achava que a mãe tinha visto a mensagem que ela tinha enviado, porque estava no celular dela, mas que esta não disse nada. Foi apontado pela psicóloga que ela parecia realmente querer que a mãe lesse e que muitas das coisas que ela fazia pareciam ter esse intuito. Ela concordou e disse que gostaria que a mãe fosse como sua madrinha, uma mulher que conversava sobre tudo com ela e não a tratava diferente dos próprios filhos. A psicóloga ressalta a importância de ela ter se dado conta da possibilidade de contar com essa pessoa e de que essa madrinha se importava com ela.

Estas últimas sessões relatadas fazem-nos ver como, aos poucos, Maria Eduarda pôde começar a recorrer a outras estratégias que não ao ato de se autoinfligir cortes na busca pelo olhar do Outro. Sua saída de casa, a mensagem que envia pelo celular da mãe e não apaga, e as cartas que começa a escrever são modos que encontra de tentar convocar o Outro materno de um modo outro que não através de cortes, e sim, de tentativas mais diretas de apelo. Neste caso, a escuta analítica - via transferência como campo de acolhimento ao sujeito- foi um instrumento importante na construção de novos recursos subjetivos diante do desamparo.

Após as sessões relatadas acima, porém, Maria Eduarda faltou por dois meses, alegando sempre que se esquecia dos horários por se ter mudado e estar com uma nova rotina, até que, no início de agosto, disse que não estava interessada no acompanhamento no momento. Em contato com sua mãe, esta disse que a filha estava há dois meses morando na casa de uma madrinha, para onde foi em função de ela ter voltado a trabalhar e passar o dia fora. Contou que a filha amava ficar lá, onde sempre tinha companhia, carinho e cuidado inclusive sua madrinha estava cuidando de suas cicatrizes com uma pomada para as mesmas sumirem - e que não via problema que os atendimentos da filha fossem suspensos. Já em contato com sua madrinha, esta disse que Maria Eduarda estava muito bem e talvez por isso não estivesse sentindo necessidade do tratamento. Contou que ela a respeitava e obedecia, e ela achava que lá a menina tinha encontrado o que sempre quis, atenção, pois elas conversavam sobre tudo e ela a orientava em relação a roupas, meninos, etc. Contou que no celular da afilhada o contato dela estava salvo como "mamis" e de seu esposo como "papis", e que no aniversário de seu esposo ela havia lhe enviado um texto dizendo que ele era como um pai que ela nunca tinha tido. Disse que, na casa da mãe, a menina não tinha ninguém e ela se preocupava que ela voltasse pra lá e voltasse a ter os comportamentos de se machucar para chamar atenção, por isso faria de tudo que pudesse para que isso não acontecesse.

Sobre a mudança de endereço da adolescente, pudemos pensar que, por um lado, traz um movimento de Maria Eduarda em busca de outras pessoas que possa tomar como referência, acolhimento e cuidado, mas, por outro, nos alerta, pelo fato de que essa mudança foi atrelada à interrupção dos atendimentos. Supomos que essa mudança talvez possa ter sido uma resposta em ato ao apontamento da psicóloga à presença de outras pessoas em sua vida, no lugar do trabalho de elaboração da falta no Outro materno. Nesse sentido, a mudança de 
endereço apenas promoveria uma reedição de suas demandas ao Outro materno, que, porém, podem responder de modos diferentes. Diante da interrupção da análise, é feita uma aposta na vida e nos futuros encontros com o Outro que o adolescente poderá vir a ter6.

Sua mudança recordou-nos o caso Dora (Freud, 1905[1901]/1996a), em que fica claro, principalmente através das postulações de Lacan (1956-1957/1995), que a partir da impossibilidade de sua mãe corresponder ao lugar de referencial feminino, ela recorre a outra mulher, a senhora K. Era impossível para Dora espelhar-se em uma mulher que nem ao menos a via, assim como para nossa paciente, e então ambas - Dora e Maria Eduarda - voltam-se a outra mulher que lhe confere um lugar em seu desejo. No caso de Maria Eduarda, essa madrinha a olha, conversa com ela, escuta-a, aconselha-a, em seu modo de se vestir e de se relacionar, e cuida de suas cicatrizes. Para além dessas marcas físicas que ela tenta cicatrizar, questionamos, porém, como ficarão e como irão reverberar futuramente as marcas psíquicas daquilo que, pelo menos até o momento, não foi possível elaborar da sua relação à mãe.

Tal questão, entretanto, traz a dimensão do impossível presente em toda análise, e talvez mais particularmente nas análises de adolescentes. Como temos visto, o trabalho de análise na adolescência muitas vezes coincide com o trabalho psíquico da adolescência, e pode se restringir a auxiliar o sujeito nos percalços do momento ou avançar e coincidir com uma análise de adulto (Coutinho, 2006). O pedido de interrupção da análise pelo adolescente, entretanto, é diferente de uma interrupção ou encerramento quando se trata de um adulto. No caso de Maria Eduarda, acreditamos que a análise pôde auxiliá-la nos percalços relativos à angústia da falta do amor materno que reatualiza sua condição de desamparo que só era possível aliviar através dos cortes autoinfligidos. A menina pôde colocar em palavras as dores associadas aos cortes, falar sobre suas demandas relacionadas ao feminino, e pensar em outras estratégias para convocar o Outro. Seu pedido de interrupção não coincide com o fim de uma análise, assim como o fim deste trabalho não dá por encerrada a análise do caso que se propôs.

\section{Referências}

Alberti, S. (2004) $O$ adolescente e o outro. Rio de Janeiro: Zahar.

Araújo, J., Scheikman, D., Carvalho, I., \& Viana, T. (2016). O corpo na dor: automutilação, masoquismo e pulsão. São Paulo, Estilos da clínica, 21(2), 497-515.

Barros, R. M. M.; Ligeiro, V. M. (2020). "O que é ser mulher?" - entre o enigma e o desamparo. Trivium - Estudos Interdisciplinares, 12(1), 313. https://dx.doi.org/10.18379/2176-4891.2020v1p.3

Birman, J. Tatuando o desamparo. (2006). In M. R. Cardoso (Org.), Adolescentes. São Paulo: Escuta. pp. 25-43.

Cavalcanti, C. A. T.; Poli, M. C.. (2015). O laço social e o mal-estar face ao desamparo. Revista Internacional Interdisciplinar INTERthesis, Florianópolis, v. 12, n. 2, p. 55-73. ISSN 1807-1384. Disponível em: <https://periodicos.ufsc.br/index.php/interthesis/article/view/18071384.2015v12n2p55 >. doi:https://doi.org/10.5007/1807-1384.2015v12n2p55.

Coutinho, L. G. (2006). Pensando sobre as especificidades da clínica psicanalítica com adolescentes. In: Latin American Journal of Fundamental Psychopathology On Line, v.6, p.44 $-55$.

Coutinho, L. G. (2009). Adolescência e Errância: Destinos do Laço Social Contemporâneo. Rio de Janeiro: Editora Nau.

Costa, A. (2003). Tatuagem e Marcas Corporais. São Paulo: Casa do Psicólogo.

Flesler, A. (2012). A psicanálise de crianças e o lugar dos pais. Rio de Janeiro: Zahar. 
Fortes, I. \& Macedo, M. (2017). Automutilação na adolescência. Psicogente. vol.20, n.38, pp.353-367. Disponível em: http://www.scielo.org.co/pdf/psico/v20n38/0124-0137psico-20-38-00353.pdf

Freud, S. (1996a). Fragmento da análise de um caso de histeria. In Freud, S. (Autor). Edição Standard Brasileira das Obras Completas de Sigmund Freud (Vol. 7, pp. 15-116). Rio de Janeiro: Imago. (Trabalho original de 1905[1901]).

Freud, S. (1996b). Três ensaios sobre a teoria da sexualidade. In Freud, S. (Autor). Edição Standard Brasileira das Obras Completas de Sigmund Freud (Vol. 7, pp. 119-231). Rio de Janeiro: Imago. (Trabalho original de 1905).

Freud, S. (1996c). Sobre as teorias sexuais da criança. In Freud, S. (Autor). Edição Standard Brasileira das Obras Completas de Sigmund Freud (Vol. 9, pp. 187-204). Rio de Janeiro: Imago. (Trabalho original de 1908).

Freud, S. (1996d). Sobre o narcisismo: Uma Introdução. In Freud, S. (Autor). Edição Standard Brasileira das Obras Completas de Sigmund Freud (Vol. 14, pp. 77-108). Rio de Janeiro: Imago. (Trabalho original de 1914).

Freud, S. (1996e). A dissolução do complexo de Édipo. In Freud, S. (Autor). Edição Standard Brasileira das Obras Completas de Sigmund Freud (Vol. 19, pp. 195-201). Rio de Janeiro: Imago. (Trabalho original de 1924).

Freud, S. (1996f). Algumas consequências psíquicas da distinção anatômica entre os sexos. In Freud, S. (Autor). Edição Standard Brasileira das Obras Completas de Sigmund Freud (Vol. 19, pp. 273-291). Rio de Janeiro: Imago. (Trabalho original de 1925).

Freud, S. (1996g). Sexualidade feminina. In Freud, S. (Autor). Edição Standard Brasileira das Obras Completas de Sigmund Freud (Vol. 21, pp. 229-254). Rio de Janeiro: Imago. (Trabalho original de 1931).

Freud, S. (1996h). Conferência XXXIII: Feminilidade. In Freud, S. (Autor). Edição Standard Brasileira das Obras Completas de Sigmund Freud (Vol. 22, pp. 113-134). Rio de Janeiro: Imago. (Trabalho original de 1933[1932]).

Kehl, M. R. (2008). Deslocamentos do feminino. Rio de Janeiro: Imago.

Lacan, J. (1995). O Seminário livro 4: a relação de objeto. Rio de Janeiro: Jorge Zahar. (Seminário original proferido em 1956-1957).

Lacan. J. (1998). A significação do falo. In: Escritos. Rio de Janeiro: Jorge Zahar. p. 692-703. (Trabalho original de 1958).

Lacan. J. (1999). O Seminário livro 5: as formações do inconsciente. Rio de Janeiro: Jorge Zahar. (Seminário original proferido em 1957-1958).

Lacan. J. (2003). Nota sobre a criança. In: Outros Escritos. Rio de Janeiro: Jorge Zahar. p. 369-370. (Trabalho original de 1969).

Lacan. J. (2005). O Seminário livro 10: a angústia. Rio de Janeiro: Jorge Zahar. (Seminário original proferido em 1962-1963).

Lacan. J. (2008). O Seminário, livro 20: mais, ainda. Rio de Janeiro: Jorge Zahar. (Seminário original proferido em 1972-1973).

Le Breton, D. (2010). Escarificações na adolescência: uma abordagem antropológica. Horizontes Antropológicos, 16(33), 25-40. https://doi.org/10.1590/S010471832010000100003 Bahia.

Miller, J-A. (1998). O osso de uma análise. Escola Brasileira de Psicanálise: Salvador,

Nasio, J.-D. (Dir.). (2001). Os grandes casos de psicose. Rio de Janeiro: J. Zahar. 244 p.

Poli, M. C. (2007). Feminino/masculino. Rio de Janeiro: Jorge Zahar. (Passo-a-passo; v.76). 
Poli, M. C. (2008). Escrevendo a psicanálise em uma prática de pesquisa. Estilos da Clinica, 13(25), 154-179. Recuperado em 14 de novembro de 2020, de http://pepsic.bvsalud.org/scielo.php?script=sci_arttext\&pid=S1415-

$71282008000200010 \& \operatorname{lng}=$ pt\&tlng=pt.

Quinet, A. (2012). Os Outros em Lacan. Rio de Janeiro: Zahar.

Saggese, E. (2015). Existe uma Clínica Específica Com Adolescentes? In: E. Saggese; F. H. Oliveira. (org.). Juventude e Saúde Mental: a especificidade da clínica com adolescentes. Rio de Janeiro: Companhia de Freud.

\section{Notas}

1. O artigo deriva da monografia de fim de curso, realizada como uma das atividades relativas ao curso de Especialização em Psicanálise e Psiquiatria com Crianças e Adolescentes do IPUB/UFRJ e constitui-se também como um dos resultados parciais do projeto de pesquisa "Educação para a vida: adolescência, suicídio e vulnerabilidades sociais" coordenado pela segunda autora deste artigo no âmbito do LAPSE/UFF (Grupo de pesquisa psicanálise, educação e laço social)

2. A pesquisa foi aprovada pelo comitê de ética em pesquisa com o CAAE no 20131119.6.0000.8160. Respeitando o sigilo profissional, todos os nomes aqui utilizados são fictícios.

3. Após a triagem, Maria Eduarda passou a ser atendida pela primeira autora do artigo, sendo a segunda autora a supervisora do caso no âmbito do curso de especialização acima mencionado.

4. É importante destacar que esta não é uma prática contemporânea, pois, desde a antiguidade, há relatos de práticas desse tipo. O que se diferencia aqui são as dimensões dessa prática, tanto no sentido quantitativo, pois temos notado seu aumento na atualidade, como no que se refere aos contextos e motivações associadas. Se antes tal prática era movida por concepções ritualísticas, e, portanto, coletivas, com sentidos próprios ligados a uma dada cultura, hoje, como buscaremos afirmar ao longo deste trabalho, ela se relaciona a questões subjetivas e singulares de cada sujeito que denotam, de diferentes formas, um modo particular de laço ao Outro (Le Breton, 2010; Costa, 2003).

5. As sessões com a mãe realmente faziam ver uma mãe um pouco ausente, que notou os cortes nos membros da filha apenas após a escola a notificar deles e que por várias vezes dizia estar tudo bem entre elas e não estar vendo mais os cortes nos braços da filha, quando estes eram visíveis durante as sessões, mesmo porque Maria Eduarda usava sempre roupas que não os velavam. A mãe esquiva-se também da presença nas sessões e, quando convocada, é sempre muito difícil construir um trabalho com ela.

6. Não podemos deixar de considerar, porém, que há aqui um elemento terceiro, o esposo de sua madrinha, que talvez possa de uma forma menos precária do que outrora, ocupar o lugar da função de corte possibilitando um rearranjo da cena em que a menina se possa desalienar da relação materna que, neste caso, a fixa numa posição de frustrada. Esta, entretanto, é apenas uma hipótese, assim como as levantadas acima.

Citação/Citation: Amaral, R. E. C.; Coutinho, L. G. (2021). O insuportável do enigma feminino em um caso de autolesão na adolescência. Trivium: Estudos Interdisciplinares (Ano XIII, Ed.2), pp. 21-36.

Recebido em: 30/11/2020 Aprovado em: 03/07/2021 